\title{
Aplikasi PCO Plus pada Tanah Bekas Tambang Batu Bata Merah terhadap Serapan P, Ca dan B serta Fruitset Cabai Merah Besar (Capsicum annuum L.)
}

\author{
Stefina Liana Sari ${ }^{1}$, Rija Sudirja ${ }^{2}$ dan Emma Trinurani Sofyan ${ }^{2}$ \\ ${ }^{1}$ Alumni Progam Studi Magister Ilmu Tanah, Fakultas Pertanian, Universitas Padjadjaran \\ J1. Jatinangor-Sumedang Km 21 Jatinangor 45363 \\ ${ }^{2}$ Departemen Ilmu Tanah dan Manajemen Sumberdaya Lahan, Fakultas Pertanian, \\ Universitas Padjadjaran \\ *Alamat korespondensi: stefinalianasari25@gmail.com
}

\begin{abstract}
Application of liquid organic fertilizer formula plus on degraded soil to improve the productivity of the land and chili (Capsicum annuum L.) production
\end{abstract}

Soil exploitation in large numbers occurred in the District Wanaraja of Garut Regency. Excavation of soil more than 2 meters from the top layer for the manufacture of red bricks has exceeded the ability of the soil to re-establish its structure. So that the soils, which were agricultural lands, can be classified as degraded soils with less fertility and chemical properties. Lans reuse for agriculture requires adequate recovery and fertilizer input. This study aimed to determine the formula of LOF (liquid organic fertilizer) plus used with NPK compound fertilizer on degraded soil to improve the soil productivity. The design used was a Simple Randomized Block Design (RBD) by 10 combinations of LOF plus treatment with NPK compound fertilizer as follows: A = Control (degraded soil, no fertilizer), B $=0 \% \mathrm{LOF}+1 \mathrm{NPK}, \mathrm{C}=0.25 \% \mathrm{LOF}+1 \mathrm{NPK}, \mathrm{D}=0.50 \% \mathrm{LOF}+1$ $\mathrm{NPK}, \mathrm{E}=0.75 \% \mathrm{LOF}+1 \mathrm{NPK}, \mathrm{F}=1.00 \% \mathrm{LOF}+1 \mathrm{NPK}, \mathrm{G}=0.5 \% \mathrm{LOF}+3 / 4 \mathrm{NPK}, \mathrm{H}=0.5 \% \mathrm{LOF}+$ $1 / 2 \mathrm{NPK}, \mathrm{I}=0.5 \% \mathrm{LOF}+1 / 4 \mathrm{NPK}, \mathrm{J}=0.5 \mathrm{LOF}+0 \mathrm{NPK}$, and $\mathrm{K}=1 \mathrm{NPK}$ of normal soil that all replicated three times. The results showed that the degraded soil of red bricks required concentration of LOF above $0.5 \%$ to $1 \%$ when applied with 1 dose of standard NPK. It is able to balance the uptake of nutrients $\mathrm{P}, \mathrm{Ca}$, and $\mathrm{B}$ and percentage of fruitset in chili commodities equivalent to normal soil.

Keywords: Chilli, Liquid Organic Faertilizer (LOF), NPK, Soil degreded

\begin{abstract}
ABSTRAK
Eksploitasi tanah dalam jumlah yang besar terjadi di Kecamatan Wanaraja, Kabupaten Garut. Terjadinya penggalian tanah lebih dari 2 meter dari lapisan atas untuk pembuatan batu bata merah melampaui kemampuan tanah untuk membentuk struktur tanah kembali, sehingga tanah-tanah yang sebelumnya merupakan tanah pertanian ini dapat digolongkan menjadi tanah terdegradasi dengan sifat kimia kurang subur dan pemanfaatan kembali untuk pertanian memerlukan pemulihan dan input pupuk yang cukup. Penelitian ini bertujuan untuk mengetahui formula pupuk cair organik (PCO) plus yang digunakan bersama NPK pada tanah terdegradasi guna meningkatkan kembali produktvitas tanahnya. Rancangan yang digunakan adalah RAK sederhana dengan 10 kombinasi perlakuan PCO plus bersama NPK yaitu A = Kontrol (tanah terdegradasi, tanpa pupuk), $\mathrm{B}=0 \% \mathrm{PCO}+1 \mathrm{NPK}, \mathrm{C}=0,25 \% \mathrm{PCO}+1 \mathrm{NPK}, \mathrm{D}=0,50 \% \mathrm{PCO}+1 \mathrm{NPK}, \mathrm{E}=0,75 \% \mathrm{PCO}+1 \mathrm{NPK}$, $\mathrm{F}=1,00 \% \mathrm{PCO}+1 \mathrm{NPK}, \mathrm{G}=0,5 \% \mathrm{PCO}+3 / 4 \mathrm{NPK}, \mathrm{H}=0,5 \% \mathrm{PCO}+1 / 2 \mathrm{NPK}, \mathrm{I}=0,5 \% \mathrm{PCO}+1 / 4$ $\mathrm{NPK}, \mathrm{J}=0,5 \mathrm{PCO}+0 \mathrm{NPK}$, dan $\mathrm{K}=1 \mathrm{NPK}$ tanah normal. Semua perlakuan diulang tiga kali. Hasil penelitian menunjukkan bahwa tanah terdegradasi bekas tambang batu bata merah memerlukan konsentrasi PCO di atas 0,5\% sampai dengan 1\% apabila diaplikasikan bersama 1 dosis NPK
\end{abstract}


standar. Hal ini mempu mengimbangi serapan hara $\mathrm{P}, \mathrm{Ca}$, dan $\mathrm{B}$ serta persen fruitset pada komoditas cabai setara dengan tanah normal.

Kata Kunci: Cabai, NPK, Pupuk Cair Organik (PCO), Tanah terdegradasi

\section{PENDAHULUAN}

Ketergantungan manusia terhadap sumberdaya tanah terus meningkat. Eksploitasi tanah secara terus-menerus dalam jumlah yang sangat besar terjadi di Kecamatan Wanaraja, Kabupaten Garut. Proses penambangan untuk pembuatan batu bata merah melampaui kemampuan tanah untuk membentuk struktur tanah kembali, sehingga tanah-tanah yang sebelumnya merupakan tanah pertanian ini dapat digolongkan menjadi tanah terdegradasi. Gejala fisik yang tampak jelas adalah semakin menipisnya lapisan tanah karena hilangnya top soil (lapisan atas), terbentuknya lubang-lubang bekas tambang dengan kedalaman 24 meter dengan luas beragam. Tanaman yang tumbuh di atas tanah tersebut menunjukkan gejala pertumbuhan yang tidak normal serta hasil panen yang menurun signifikan. Berdasarkan data analisis Laboratorium Kesuburan Tanah Fakultas Pertanian Universitas Padjadjaran, tanah bekas tambang batu bata merah di Wanaraja Kabupaten Garut merupakan tanah Inceptisol dengan sifat kimia tanah kurang subur dan pemanfaatan kembali untuk bidang pertanian memerlukan pemulihan dan input pupuk yang cukup.

Formula pupuk cair organik (PCO) plus merupakan salah satu temuan yang dapat menjadi solusi. Formula ini merupakan hasil dari pengelolaan limbah ternak sapi secara optimal yaitu dengan cara mengubah limbah padat menjadi cair dengan tambahan molase sehingga menjadi senyawa organik yang mampu berperan sebagai pembenah tanah juga diperkaya dengan bahan mineral (Anonim, 2011) untuk melengkapi kebutuhan unsur hara makro dan mikro bagi tanaman. Formula PCO plus, dapat menjadi altnatif pemanfaatan kembali tanah Inceptisol bekas tambang batu bata yang kurang subur untuk bidang pertanian, khususnya untuk komoditas hortikultura.

Cabai merah (Capsicum annum. L) merupakan salah satu komoditas hortikultura yang penting di Indonesia. Berdasarkan data Badan Pusat Statistik (2015), produksi dan luas panen cabai dari tahun 2011 sampai tahun 2015 terus berubah. Ratarata produktivitas cabai nasional baru mencapai 8.06 ton/ha, sementara potensi produksi cabai dapat mencapai 10,9 ton/ha. Dapat diasumsikan bahwa produksi cabai masih dapat ditingkatkan hingga 20,12\% dari potensi produksi. Menurut Badan Pusat Statistik (2015), pemerintah harus mengimpor cabai yang mencapai lebih dari 338 ton per tahun, hal ini membuktikan permintaan masyarakat Indonesia terhadap cabai yang cukup tinggi. Dengan kata lain, produksi cabai di Indonesia belum mampu memenuhi kebutuhan cabai nasional.

Hasil tanaman cabai yang tinggi salah satunya dipengaruhi oleh jumlah bunga yang mampu berkembang hingga menjadi buah. Persentase jumlah bunga yang muncul dibandingkan dengan jumlah buah yang terbentuk dari bunga tersebut dinyatakan dengan fruitset. Akan tetapi, rentannya tanaman cabai terhadap pengguguran bunga dan buah menjadi salah satu masalah yang serius bagi para petani cabai. Menurut Kang (1989) dan Enril (1989) dalam Koesriharti dkk. (1999) hal tersebut dapat menyebabkan penurunan produksi yang signifikan. Salah satu usaha untuk mengatasi pengaruh kondisi tersebut agar terjadinya pembungaan, pembentukan buah dan hasil cabai yang tinggi yaitu dengan pemberian hara yang mencukupi diantaranya fosfor (P), sulfur (S), kalsium (Ca), dan boron (B) yang memiliki peranan penting dalam proses fisiologis tanaman terutama pada stadia pembungaan dan pembuahan.

Pada fase generatif tanaman, $\mathrm{P}$ berperan dalam pembentukan primordia bunga, pembentukan organ tanaman reproduksi lainnya, serta mempercepat pemasakan buah dan biji (Rosmarkam \& Yuwono, 2002). Kekurangan $\mathrm{P}$ pada tanaman cabai pada awal fase generatif dapat menghambat pembentukan bunga, sehingga jumlah bunga akan lebih sedikit. Proses pembungaan dan pembuahan juga dipengaruhi oleh Ca dan B. Unsur Ca berperan pada pertumbuhan apikal dan pembentukan bunga, kekurangan Ca menyebabkan bunga kuncup akan sulit membuka. Ca juga berperan dalam pembelahan sel, permeabilitas sel hingga mempengaruhi kualitas buah. Konsentrasi Ca yang rendah pada jaringan tanaman dapat menjadi penyebab utama berbagai gangguan fisiologis dimana yang paling sering terjadi adalah berupa pembusukan pada ujung buah (blossom-end rot) (Kowalska \& Sady, 2012; Michalojc \& Dzida 2012). Sedangkan B 
memengaruhi hasil penyerbukan dan perkembangan biji dalam buah yang terbentuk serta perkembangan buah normal. Kekurangan boron menyebabkan buah retak, pembentukan buah yang tidak normal, pemasakan tidak merata dan warna buah pucat kemerahan hingga kecoklatan. Selain itu, perkembangan tabung serbuk sari menjadi terganggu. Formula PCO plus diharapkan dapat dimanfaatkan secara sebagai solusi untuk pemulihan dan peningkatan sifat kimia tanah bekas tambang batu bata merah serta dalam upaya peningkatan produktivitas cabai.

\section{BAHAN DAN METODE}

Penelitian dimulai pada bulan Januari sampai dengan Mei 2017 yang terdiri atas beberapa rangkaian kegiatan di laboratorium dan lapangan. Formulasi POC dan analisis kandungan hara PCO dilakukan di Laboratorium Kesuburan Tanah dan Nutrisi Tanaman, Departemen Ilmu Tanah dan Sumberdaya Lahan, Fakultas Pertanian, Universitas Padjadjaran, Jatinangor. Aplikasi pada tanaman cabai menggunakan polybag dengan media tanah Inceptisol terdegradasi akibat tambang batu bata merah yang berasal dari Wanaraja Kabupaten Garut. Pelaksanaan penanaman dilakukan di Kebun Percobaan Fakultas Pertanian Universitas Padjadjaran Jatinangor yang terletak pada ketinggian \pm 768 meter di atas permukaan laut. Kegiatan setelah penanaman adalah analisis jaringan tanaman di Laboratorium Kesuburan Tanah dan Nutrisi Tanaman, Departemen Ilmu Tanah dan Sumberdaya Lahan, Fakultas Pertanian Universitas Padjadjaran, Jatinangor.

Bahan yang digunakan dalam percobaan ini antara lain kotoran sapi yang berasal dari Kabupten Garut, tanah Inceptisol Wanaraja, Kabupaten Garut, bahan-bahan mineral sumber hara tambahan pupuk (Molase sebagai sumber karbon organik, ZA $\left[\left(\mathrm{NH}_{4}\right)_{2} \mathrm{SO}_{4}\right]$ sebagai sumber nitrogen dan sulfur, Sp36 dan $\mathrm{KCl}$ sebagai sumber fosfor dan kalium, serta $\mathrm{FeSO}_{4} .7 \mathrm{H}_{2} \mathrm{O}, \quad \mathrm{MnSO}_{4} .4 \mathrm{H}_{2} \mathrm{O}, \quad \mathrm{CuSO}_{4} .5 \mathrm{H}_{2} \mathrm{O}$, $\mathrm{ZnSO}_{4} . \mathrm{H}_{2} \mathrm{O}, \quad \mathrm{Na}_{2} \mathrm{~B}_{4} \mathrm{O}_{7} .5 \mathrm{H}_{2} \mathrm{O}, \mathrm{Co}\left(\mathrm{NO}_{3}\right) 2.6 \mathrm{H}_{2} \mathrm{O}$, dan

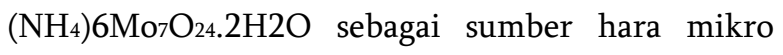
besi, mangan, tembaga, seng, natrium, cobalt dan molybdenum dan benih cabai merah besar yang digunakan adalah varietas Unpad CB1.

Penelitian ini menggunakan metode eksperimen Rancangan Acak Kelompok (RAK)
Sederhana atau Simlpe Randomize Block Design yang terdiri dari kombinasi perlakuan konsentrasi PCO dan dosis NPK. Total perlakuan kombinasi berjumlah 10 dengan uraian sebagai berikut: $\mathrm{A}=$ Kontrol (tanah terdegradasi, tanpa pupuk), $\mathrm{B}=0 \%$ $\mathrm{PCO}+1 \mathrm{NPK}, \mathrm{C}=0,25 \% \mathrm{PCO}+1 \mathrm{NPK}, \mathrm{D}=0,50 \%$ $\mathrm{PCO}+1 \mathrm{NPK}, \mathrm{E}=0,75 \% \mathrm{PCO}+1 \mathrm{NPK}, \mathrm{F}=1,00 \%$ $\mathrm{PCO}+1 \mathrm{NPK}, \mathrm{G}=0,5 \% \mathrm{PCO}+3 / 4 \mathrm{NPK}, \mathrm{H}=0,5 \%$ $\mathrm{PCO}+1 / 2 \mathrm{NPK}, \mathrm{I}=0,5 \% \mathrm{PCO}+1 / 4 \mathrm{NPK}, \mathrm{J}=0,5$ $\mathrm{PCO}+0 \mathrm{NPK}$, dan $\mathrm{K}=1 \mathrm{NPK}$ tanah normal. Setiap perlakuan diulang sebanyak tiga kali, sehingga secara keseluruhan jumlah unit percobaan adalah 10 x 3, yaitu 30 unit percobaan. Setiap unit percobaan merupakan 2 individu tanaman, 1 tanaman untuk pengamatan hingga penghitungan fruitset, dan satu sampel lainnya merupakan sampel destruksi untuk analisis jaringan tanaman yang akan dilakukan pada vegetatif maksimum.

\section{HASIL DAN PEMBAHASAN}

\section{Serapan P, Ca dan B}

Hasil analisis laboratorium untuk serapan $\mathrm{P}$, Ca, dan B serta uji statistiknya disajikan pada Tabel 1. Hasil uji statistik dari serapan $P, C a$ dan B menunjukkan angka yang signifikan. Hal ini berarti bahwa pemberian PCO plus bersama NPK mampu meningkatkan serapan $\mathrm{P}, \mathrm{Ca}$ dan $\mathrm{B}$ tanaman cabai. Serapan $\mathrm{P}$ tertinggi ditunjukkan oleh perlakuan konsentrasi PCO 1\% dengan 1 dosis NPK standar petani serta perlakuan dengan konsentrasi PCO bersama dosis NPK yang lebih tinggi yaitu 0,50\% $\mathrm{PCO}+1$ NPK, 0,75\% PCO + 1 NPK, G = 0,5\% PCO + 3/4 NPK dan perlakuan 1 NPK tanah normal.

Serapan Ca tertinggi juga ditunjukkan oleh perlakuan dengan dosis NPK bersama konsentrasi PCO tertinggi yaitu perlakuan 0,75\% PCO + 1 NPK dan $1,00 \%$ PCO + 1 NPK yang sama tinggi dengan perlakuan pembanding (tanah normal). Begitu pula dengan serapan $\mathrm{B}$, serapan tertinggi merupakan perlakuan dosis NPK standar dengan 1\% PCO plus yang hasilnya dapat mengimbangi serapan $\mathrm{B}$ pada tanah normal. Hal tersebut menunjukkan bahwa pemanfaatan PCO plus pada tanah terdegradasi bekas tambang batu bata merah perlu diperlukan dalam konsentrasi 1\% apabila diaplikasikan bersama NPK yang biasa digunakan petani setempat karena dosis pada perlakuan ini dapat meningkatkan serapan $\mathrm{P}, \mathrm{Ca}$, dan $\mathrm{B}$ setara dengan tanah normal yang diberi perlakuan NPK standar. 
Tabel 1. Serapan P, Ca dan B.

\begin{tabular}{|c|c|c|c|c|}
\hline Perlakuan & Serapan P (\%) & Serapan $\mathrm{Ca}(\mathrm{ppm})$ & Serapar & $\mathrm{B}(\mathrm{ppm})$ \\
\hline Kontrol (tanpa pupuk) & $0,64 \quad \mathrm{a}$ & $1,98 \quad \mathrm{a}$ & 30,28 & $\mathrm{a}$ \\
\hline $0 \mathrm{POC}+1 \mathrm{NPK}$ & 5,42 & 10,18 & 206,48 & bc \\
\hline $0,25 \mathrm{PCO}+1 \mathrm{NPK}$ & 5,90 & 10,71 & 243,45 & $\mathrm{~cd}$ \\
\hline $0,50 \mathrm{PCO}+1 \mathrm{NPK}$ & 8,69 & 13,80 & 312,59 & e \\
\hline $0,75 \mathrm{PCO}+1 \mathrm{NPK}$ & 8,42 & 16,69 & 324,06 & e \\
\hline $1,00 \mathrm{PCO}+1 \mathrm{NPK}$ & 9,22 & 16,64 & 378,51 & $\mathrm{f}$ \\
\hline $0,5 \mathrm{PCO}+3 / 4 \mathrm{NPK}$ & 8,54 & 14,21 & 339,26 & e \\
\hline $0,5 \mathrm{PCO}+1 / 2 \mathrm{NPK}$ & 7,12 & 11,93 & 264,55 & $\mathrm{~d}$ \\
\hline $0,5 \mathrm{PCO}+1 / 4 \mathrm{NPK}$ & 6,04 & 11,13 & 242,62 & bc \\
\hline $0,5 \mathrm{PCO}+0 \mathrm{NPK}$ & 5,70 & 10,24 & 199,71 & $\mathrm{~b}$ \\
\hline 1 NPK tanah normal & 8,15 & 16,79 & 382,94 & $\mathrm{f}$ \\
\hline
\end{tabular}

Jumlah Bunga, Jumlah Buah dan Persentase Fruitset Jumlah bunga diperoleh dengan menghitung bunga yang mekar setiap 2 hari, sejak pembungaan ketiga hingga 5 kali penghitungan, yaitu pada 28 hari setelah tanam (HST), 32 HST, 36 HST, 40 HST, dan 42 HST. Data lengkap dapat dilihat pada Tabel 2. Hasil pengamatan lapangan menunjukkan tanaman dengan perlakuan $1,00 \%$ PCO + 1 NPK berbunga lebih cepat yaitu sejak 21 HST, namun rata rata tanaman serempak berbunga sejak 28 HST. Hingga 44 HST dapat dilihat bahwa jumlah bunga tertingggi adalah pada perlakuan $0,50 \%$ PCO + 1 NPK, diikuti perlakuan $0,75 \%$ PCO +1 NPK dan $0,5 \%$ PCO + 1/2 NPK. Selanjutnya untuk mengetahui jumlah bunga yang mempu berkembang hingga menjadi buah dihitung sejak 34 HST, 38 HST, 42 HST, 46 HST, dan 50 HST (Tabel 3). Hasil penghitungan menunjukkan jumlah buah tertinggi merupakan perlakuan $0,50 \% \mathrm{PCO}+1 \mathrm{NPK}$, $0,75 \%$ PCO + 1 NPK, $1,00 \%$ PCO + 1 NPK, $0,5 \%$ PCO + 3/4 NPK dan 1 NPK tanah normal. Jumlah buah yang muncul dari perkembangan bunga tanaman cabai yang ditanam pada tanah terdegradasi bekas tambang batu bata merah yang diberi PCO bersama NPK pada dosis yang tidak dikurangi, ratarata hampir setara dengan jumlah bunga dan buah pada tanah normal.

Tabel 2. Rata-rata jumlah bunga pada berbagai perlakuan konsentrasi PCO dengan dosis NPK.

\begin{tabular}{lccccc}
\hline \multicolumn{1}{c}{ Perlakuan } & 28 HST & 32 HST & 36 HST & 40 HST & 44 HST \\
\hline Kontrol (tanpa pupuk) & 1 & 1 & 6 & 14 & 17 \\
0 POC + 1 NPK & 1 & 4 & 11 & 32 & 48 \\
0,25 PCO + 1 NPK & 1 & 5 & 12 & 34 & 50 \\
0,50 PCO + 1 NPK & 3 & 6 & 13 & 42 & 71 \\
0,75 PCO + 1 NPK & 1 & 5 & 13 & 35 & 54 \\
1,00 PCO + 1 NPK & 1 & 4 & 11 & 30 & 47 \\
0,5 PCO + 3/4 NPK & 0 & 5 & 11 & 33 & 46 \\
0,5 PCO + 1/2 NPK & 2 & 3 & 12 & 35 & 54 \\
0,5 PCO + 1/4 NPK & 1 & 5 & 7 & 24 & 43 \\
0,5 PCO + 0 NPK & 0 & 3 & 9 & 29 & 40 \\
1 NPK tanah normal & 1 & 5 & 12 & 27 & 47 \\
\hline
\end{tabular}

Gambar 1 menunjukkan persentase fruitset cabai merah varietas Unpad CB-1 dengan beragam perlakuan konsentrasi PCO dengan dosis NPK pada beberapa waktu pengamatan. Pada 28 HST (fruitset ketiga) hampir semua perlakuan menunjukkan persentase fruitset $100 \%$. Pada penghitungan pertama ini (fruitset ketiga), jumlah bunga yang terbentuk rata-rata masih 1 bunga dan hampir semua menjadi buah. Kecuali perlakuan D $(0,50 \%$ $\mathrm{PCO}+1 \mathrm{NPK})$ yang memiliki bunga lebih banyak 
namun terdapat bungga gugur, serta perlakuan $G$ $(0,5 \% \mathrm{PCO}+3 / 4 \mathrm{NPK})$ dan J (0,5 PCO + 0 NPK G) yang belum menghasilkan bunga. Pada pengamatan kedua (fruitset keempat) hanya perlakuan A (kontrol) dengan fruitset 100\% namun jumlah bunga dan buah terrendah. Perlakuan lainnya pada fruitset keempat hingga penghitungan fruitset kelima, PCO dengan NPK belum menunjukkan pengaruhnya. Dari penghitungan fruitset keenam dan ketujuh mulai terlihat behwa pemberian PCO dengan NPK rata-rata dapat meningkatkan persentase fruitset cabai pada tanah bekas tambang batu bata merah ini dengan hasil yang hampir setara dengan tanah normal (perlakuan K).
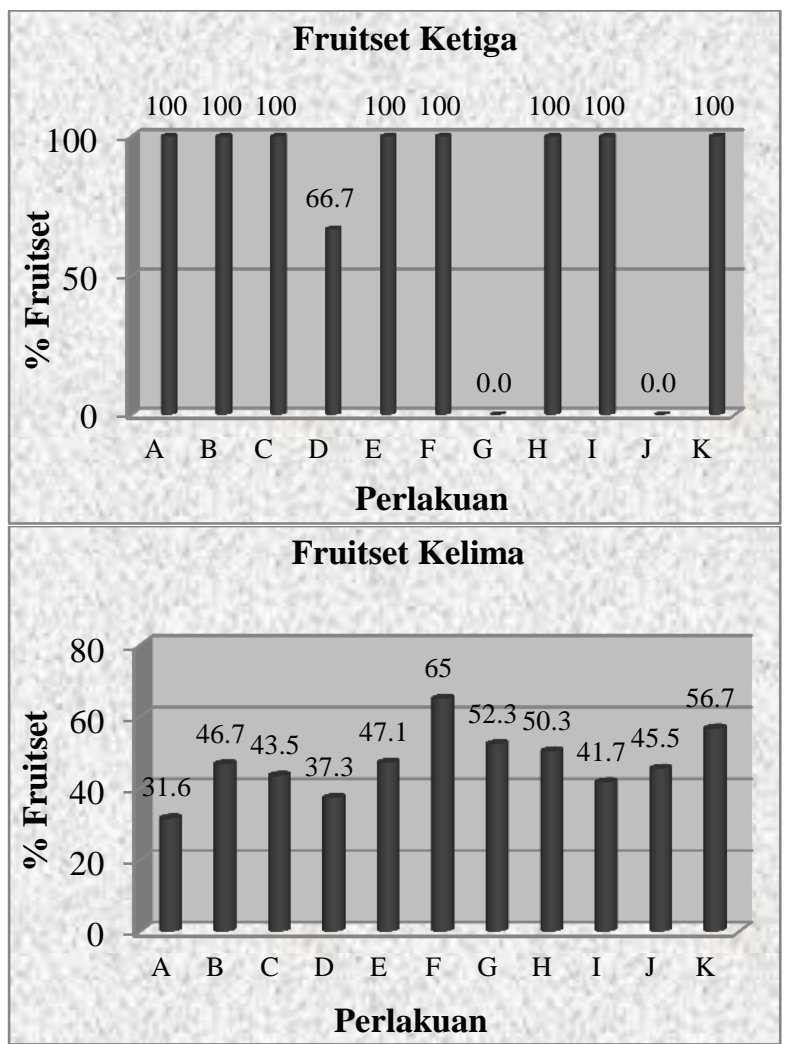
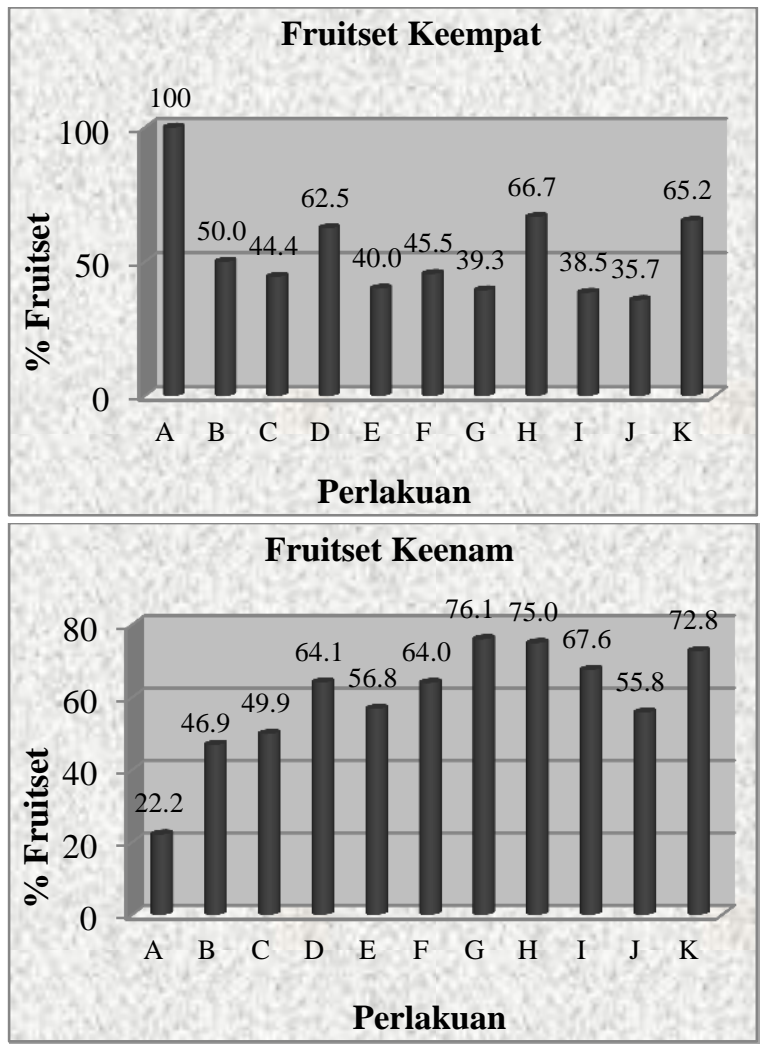

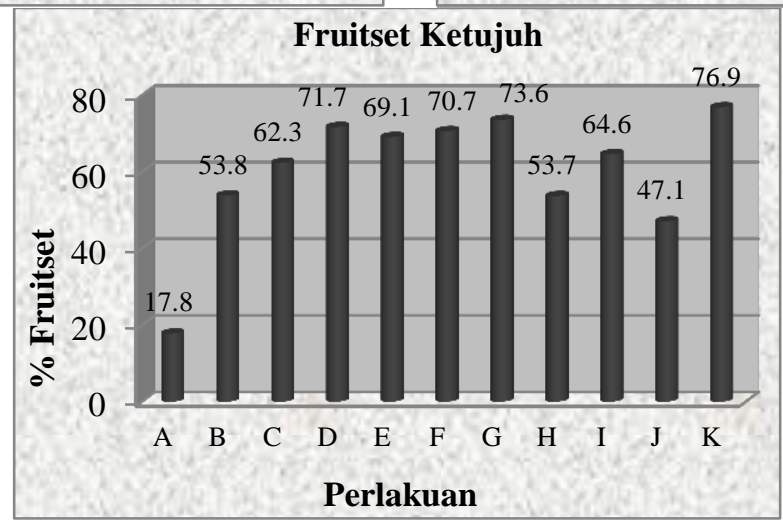

Gambar 1. Persentase fruitset cabai merah varietas Unpad CB-1 dengan beragam perlakuan konsentrasi PCO dengan dosis NPK pada beberapa waktu pengamatan. $\mathrm{A}=$ Kontrol (tanpa pupuk), $\mathrm{B}=0 \% \mathrm{PCO}+1$ $\mathrm{NPK}, \mathrm{C}=0,25 \% \mathrm{PCO}+1 \mathrm{NPK}, \mathrm{D}=0,50 \% \mathrm{PCO}+1 \mathrm{NPK}, \mathrm{E}=0,75 \% \mathrm{PCO}+1 \mathrm{NPK}, \mathrm{F}=1,00 \%$ $\mathrm{PCO}+1 \mathrm{NPK}, \mathrm{G}=0,5 \% \mathrm{PCO}+3 / 4 \mathrm{NPK}, \mathrm{H}=0,5 \% \mathrm{PCO}+1 / 2 \mathrm{NPK}, \mathrm{I}=0,5 \% \mathrm{PCO}+1 / 4 \mathrm{NPK}, \mathrm{J}=0,5$ PCO+0 NPK, dan K = 1 NPK tanah normal. 
Tabel 3. Rata-rata jumlah buah pada berbagai perlakuan konsentrasi PCO dengan dosis NPK.

\begin{tabular}{lccccc}
\hline \multicolumn{1}{c}{ Perlakuan } & 34 HST & 38 HST & 42 HST & 46 HST & 50 HST \\
\hline Kontrol (tanpa pupuk) & 1 & 1 & 2 & 3 & 3 \\
0 POC + 1 NPK & 1 & 2 & 5 & 15 & 26 \\
0,25 PCO + 1 NPK & 1 & 2 & 5 & 17 & 31 \\
0,50 PCO + 1 NPK & 2 & 4 & 5 & 27 & 51 \\
0,75 PCO + 1 NPK & 1 & 2 & 6 & 20 & 37 \\
1,00 PCO + 1 NPK & 1 & 2 & 7 & 19 & 33 \\
0,5 PCO + 3/4 NPK & 0 & 2 & 6 & 25 & 34 \\
0,5 PCO + 1/2 NPK & 2 & 2 & 6 & 26 & 29 \\
0,5 PCO + 1/4 NPK & 1 & 2 & 3 & 16 & 28 \\
0,5 PCO + 0 NPK & 0 & 1 & 4 & 16 & 19 \\
1 NPK tanah normal & 1 & 3 & 7 & 20 & 36 \\
\hline
\end{tabular}

\section{SIMPULAN}

Aplikasi PCO dnegan NPK pada tanah terdegradasi bekas tambang batu bata merah dapat meningktkan serapan $\mathrm{P}, \mathrm{Ca}$ dan $\mathrm{B}$ tanaman. Tingginya serapan hara tersebut memengaruhi terhadap gugurnya bunga dan pembentukan buah. Namun tingginya jumlah bunga dan buah tiadak selalu menunjukkan persentase fruitset tertinggi.

\section{DAFTAR PUSTAKA}

Anonim. 2011. Peraturan Menteri Pertanian Nomor 70/Permentan/SR.140/10/2011 tentang Pupuk Organik, Pupuk Hayati dan Pembenah Tanah. Kementerian Pertanian Republik Indonesia.

Badan Pusat Statistik. 2015. Produksi Cabai Besar, Cabai Rawit, dan Bawang Merah. Berita Resmi Statistik Provinsi Jawa Barat.
Tersedia online pada: ww.bps.go.id/new/website/brs_ind/brsInd20150803144409. (diakses 2 April 2017).

Koesriharti, M Maghfoer, T Islami, Respatijarti, dan N Aini. 1999. Pengaruh pemberian $\mathrm{Ba}+\mathrm{GA}$ 3 + AVG terhadap kerontokan buah pada empat kultivar tanaman lombok besar (Capsicum annuum L.). Jurnal Penelitian Ilmu-Ilmu Hayati (life Science). 11(1):5969.

Kowalska, I, and W Sady. 2012. Effect of nitrogen form, type of polyethylene film covering the tunnel and stage of fruit development on calcium content in sweet pepper fruits. Acta Sci Pol Hortorum Cultus. 11:91-100.

Michalojc, Z, and K Dzida. 2012. Yielding and biological value of sweet pepper fruits depending on foliar feeding using calcium. Acta Sci Pol Hortorum Cultus. 11: 255-264.

Rosmarkam, A dan NW Yuwono. 2002. Ilmu Kesuburan Tanah. Kanisius, Yogyakarta. 